\title{
ABNORMAL INCISORS OF MARMOTA MONAX L.
}

\author{
CHARLES A. SHULL \\ Transylvania University, Lexington, $\mathrm{Ky}$.
}

THE common woodchuck or ground hog, Marmota monax, is found rather frequently in most parts of central Kentucky; and, since it occupies the same burrows, or others in the immediate vicinity, generation after generation, it is not uncommon to find in these regions portions of their skeletons, skulls, vertebræ, teeth, etc., in the neighborhood of their habitations.

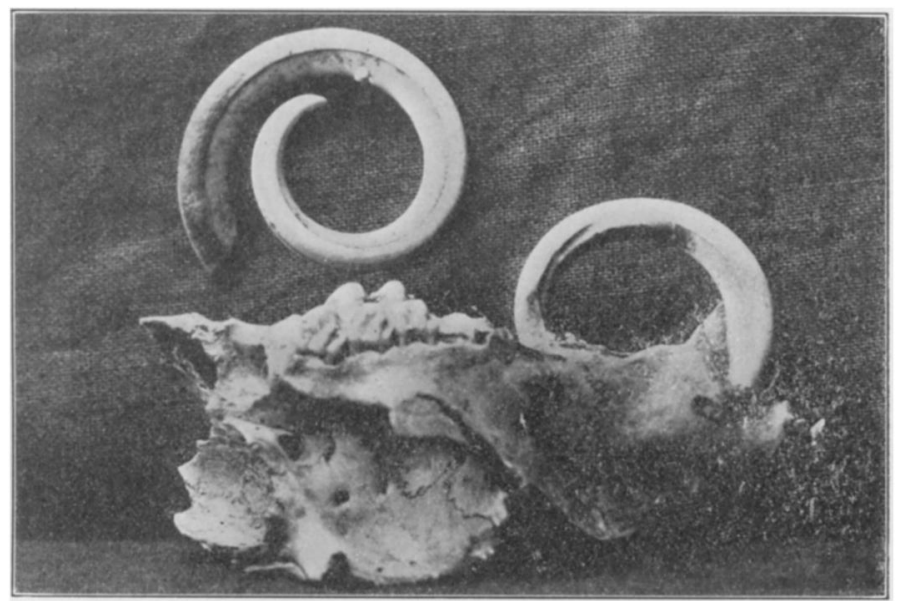

Fig. 1. Skull of Marmota monax L., right incisor removed. Natural size. Photograph by Spengler, Lexington, Ky.

The interesting specimen which is illustrated here was found near Silver Creek, Madison Co., Ky., by Mr. Charles Meeks, who presented it to Mr. Thomas Goff, of Lexington, $\mathrm{Ky}$. It has recently been given to the $\mathrm{Mu}$ seum of Transylvania University. The upper incisors are extremely long and curved so as to form with the parts imbedded in the premaxilla more than a complete 
circle. This is beautifully illustrated by Fig. 1; in which the right incisor has been removed from the jaw.

Both teeth are turned somewhat toward the right, so that the right one projects from the mouth; but the left incisor strikes the roof of the mouth to the right of the median suture, piercing the palatine plate of the maxilla

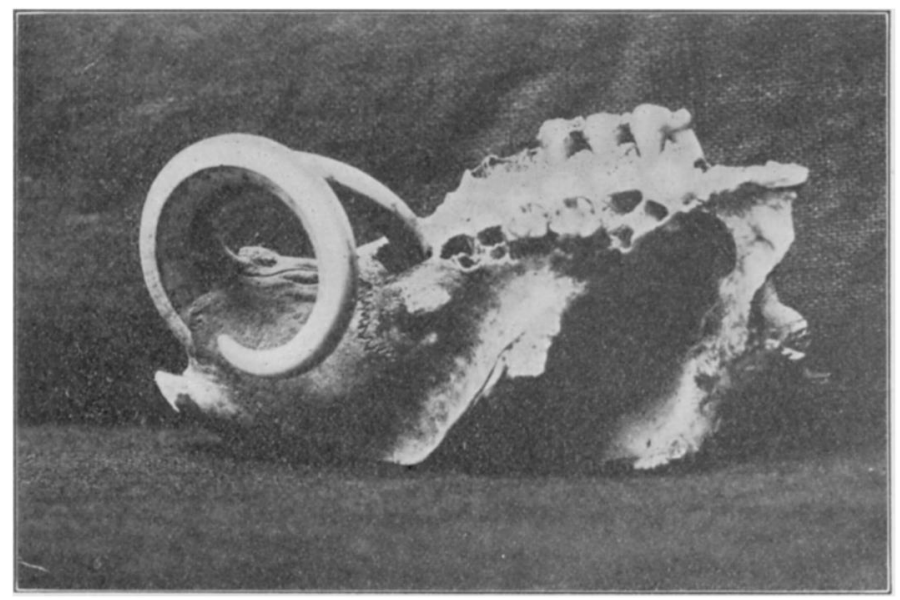

Fig. 2. Skull of M. monax L., with left incisor piercing palatine plate of right maxilla. Natural size. Photograph by Spengler, Lexington, Ky.

(Fig. 2) and extending through it to a distance of about $5 \mathrm{~mm}$. The left tooth is not as long as the right one, its growth having been retarded, perhaps by the hardness of the bone it penetrated.

The manner in which the teeth of Marmota monax grow is familiar to all who know the Rodentia. The rodents all have a diphyodont dentition, that is, there are two sets of teeth, a temporary or deciduous set, and a permanent set. But the permanent teeth never cease to grow. There is a persistent pulp at the base of each tooth, which grows throughout the life of the individual.

Ordinarily the corresponding teeth of the upper and lower jaw oppose each other perfectly, and the growth from the pulp only compensates for the amount worn off by biting. The incisors have a heavier coat of enamel on 
the anterior portion of the tooth, and the more rapid wearing of the posterior edge keeps these front teeth chisel-like and sharp.

The abnormal growth of the incisors will occur whenever the upper and lower teeth fail to meet. An injury to either jaw, as for instance a bullet wound, might destroy the perfect opposition of the incisors. But the teeth in this specimen are sharp pointed and not worn at the distal end, as they would be if they had ever functioned properly, which fact would indicate that the wound must have occurred before the permanent teeth appeared.

A careful examination shows that the abnormality can be accounted for in another way. The socket of the left incisor is not normal in its position, and the tooth itself grows inward toward the right incisor, striking it about $8 \mathrm{~mm}$. from the jaw. The latter tooth has on its inner side a groove extending from near the distal end to the point where the two incisors are in contact. This groove was produced by the pressure of the left incisor upon the right, and this pressure is undoubtedly the cause of the failure of both teeth to meet the lower ones. The abnormal growth then depended primarily upon a congenital abnormality in the position and direction of the socket of the left incisor. One of the lower teeth of the same skull was found, but has been misplaced. Mr. Goff informs me that it also was curved and much longer than usual.

It would be of interest to know how the animal with this curious set of teeth obtained food sufficient to prevent starvation. It may well be that this abnormality was the chief determining factor in its struggle for existence. 